\title{
Pyramidal Lobe Variations of the Thyroid Gland and Its Clinical Implications: A Short Review and Case Report
}

\author{
Nagavalli Basavanna Pushpa ${ }^{1^{*}}$ (D), Rohan Karkra1, Kunjappagounder Pushpalatha1, \\ Deepa Bhat ${ }^{1}$
}

\begin{abstract}
The thyroid gland is characterized by significant anatomical variability, which may lead to difficulties in diagnostic and treatment outcomes. The pyramidal lobe is the most common variation present in up to $30 \%$ of the population. Literature has witnessed research on different variations of the pyramidal lobe, preference for the lobe from which it arises, gender preference, etc. Understanding such variations is essential for successful treatment outcomes for thyroid diseases. This short review was aimed to highlight embryological aspects of the thyroid gland, variation of its pyramidal lobe and present a rare case of demarcated left lobe, pyramidal lobe, and an associated cyst.

Keywords

Thyroid Gland; Pyramidal Lobes; Anatomy; Variations; Dissection

${ }^{1}$ Department of Anatomy, JSS Medical College, JSSAHER, Mysuru, Karnataka, India

*Corresponding author: nb.pushpa@gmail.com

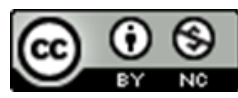

Copyright @Nagavalli Basavanna Pushpa, Rohan Karkra Kunjappagounder Pushpalatha, Deepa Bhat, 2022
\end{abstract}

\section{Background}

The thyroid gland is a bilobed endocrine organ in the lower part of the anterior neck. The lower two thirds of each lobe are connected by a median isthmus. Although the morphology of the gland varies to some extent, each lobe weighs

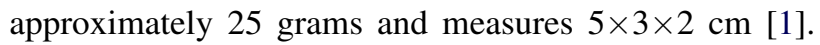
The gland extends up to the thyroid cartilage superiorly and the $4^{\text {th }}-6^{\text {th }}$ tracheal cartilage rings inferiorly, corresponding to C5-T1 vertebral levels [2]. The thyroid gland is supplied by the superior and inferior thyroid arteries which are the branches of the external carotid artery and the thyrocervical trunk, respectively [1].

\section{Embryology}

Embryonically, the thyroid gland originates as an epithelial proliferation at the base of the tongue between the copula linguae and the tuberculum impar. The thyroglossal duct is formed that proliferates and moves caudally. The thyroid gland descends through the thyroglossal duct as a bilobed diverticulum. Ultimately, the duct degenerates by the $5^{\text {th }}$ week of embryonic life [3, 4]. Common defects in thyroid embryogenesis include the presence of the pyramidal lobe, thyroglossal cyst, accessory tissue along the pathway of thyroid descent, accessory small thyroidea ima artery [5].

In some cases, the pyramidal lobe of the thyroid gland, also known as Lalouette pyramid [6], is seen as an additional lobe, extending from the isthmus up to the hyoid bone. While varying prevalence rates have been reported, the prevalence rate for this condition is estimated to be approximately $20-30 \%$, with several reports of even up to $60 \%[7,8]$. The pyramidal lobe is a remnant of the thyroglossal duct [5]. Most thyroid diseases can be associated with this condition. Knowledge of such pyramidal lobes is essential for safe and effective thyroidectomy surgeries [9].

\section{Pyramidal Lobe Variation}

The pyramidal lobe is a normal, commonly incidental finding on imaging that can be associated with all pathological conditions affecting the left and right lobes of the thyroid gland, such as adenomas, cysts, carcinomas, etc. Based on morphologic appearance, the pyramidal lobe can be classified as broad (having a broad originating base that involves both lobes), parallel (conical elongation arising from either one or both lobes), bulge (having a rounded bulge at the end of the conical elongation) or ectopic (when the lobe is not a continuation of the thyroid gland proper) [10]. Its form may be inverted Y, string-like or nodule [11]. 


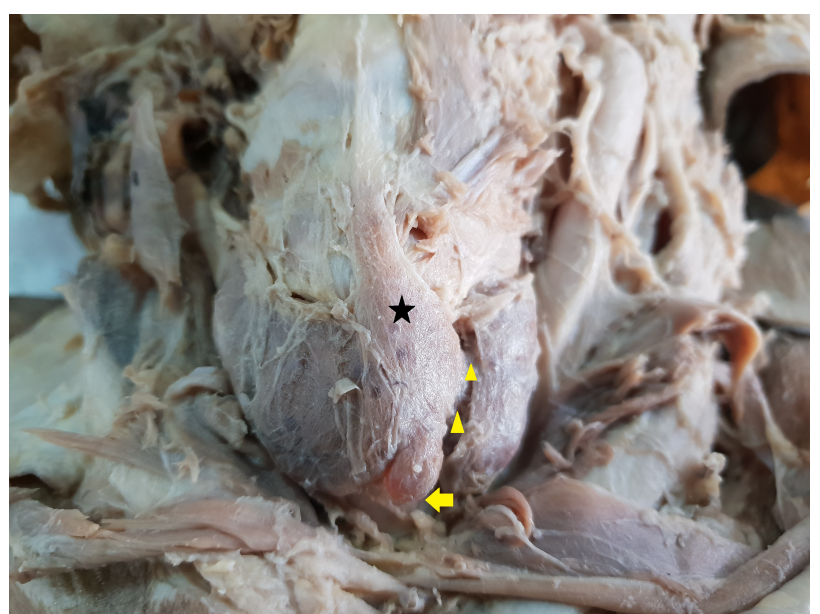

Figure 1. Specimen showing pyramidal lobe. Notes: $\star$ - pyramidal lobe, $\leftarrow-$ cyst, $\boldsymbol{\Delta}-$ abnormal left lobe separated anteriorly isthmus.

Studies conducted by Kim et al. [12] have demonstrated the efficacy of ultrasound in detecting these additional lobes. Confirming the presence of pyramidal lobes is essential prior to thyroid surgery as unawareness of the surgeon may result in non-resection of thyroid tissue postoperatively. In addition, this lobe, like other thyroid lobes, can undergo pathological changes with widespread clinical manifestations. There is controversy regarding gender preference for the occurrence of the pyramidal lobe, but the pyramidal lobe has been shown to be more common in women owing to the increased incidence of thyroid pathologies in women [13, 14]. However, the pyramidal lobe is usually longer in females than in males. Most often, the base of the pyramidal lobe is located on the isthmus, followed by the left lobe and rarely on the right lobe. As the incidence, location and morphology of the pyramidal lobe pose a great challenge during total thyroidectomy, their thorough knowledge is essential for meticulous dissection of the pre-laryngeal region during surgery $[15,16]$. Total thyroidectomy demands complete extirpation of the thyroid gland, which is essential for preventing recurrence of thyroid disease, as well as for successful adjuvant radioactive iodine therapy and effective subsequent monitoring of serum thyroglobulin levels [17].

During a routine dissection of the head and neck region for educational purposes at our institution, a 50-year-old female cadaver with an anomalous thyroid gland was found. Upon careful inspection of the thyroid gland, there was noted a pyramidal lobe, or Lalouette pyramid, with cyst, arising from the isthmus and attached to the hyoid bone by fibrous tissue (Fig. 1). According to Dessie MA, the pyramidal lobe arising from the isthmus or its junction with the right lobe occurs in 9.5-23.8\% of anomaly cases [18]. The left lobe appeared abnormal in shape and anteriorly separated from the isthmus but connected by a narrow tissue only posteriorly.

\section{Conclusions}

In conclusions, thyroid variants are common among human population and the pyramidal lobe is one the most common variation of these. There is also scientific evidence that pyramidal lobes can be affected by clinical conditions that affect other thyroid lobes. In this paper, a rare variant of the thyroid gland with the pyramidal lobe, its cyst, and incompletely separated left lobe was described. It is of great importance due to unreliable identification of this lobe, its anatomical variations preoperatively which may have an impact on medical interventions in the clinic of thyroid diseases.

\section{Ethical Statement}

No approval of institutional review board was required.

\section{Conflict of Interest}

The authors declare that no conflicts exist.

\section{Financial Disclosure}

The authors declared no financial support.

\section{References}

[1] Standring S, editor. Gray's anatomy: the anatomical basis of clinical practice. Elsevier; 2021.

[2] Policeni BA, Smoker WRK, Reede DL. Anatomy and embryology of the thyroid and parathyroid glands. Seminars in Ultrasound, CT and MRI. 2012;33(2):104-114. Available from: https://doi.org/10.1053/j.sult.2011.12.005

[3] Schoenwolf GC, Bleyl SB, Brauer PR, FrancisWest PH, Larsen WJ. Larsen's human embryology. Philadelphia: Elsevier; 2021.

[4] Maneenin C, Maneenin N, Iamsaard S. Anatomical variations of thyroid glands in NortheasternThai embalmed cadavers. International Journal of Morphology. 2019;37(1):136-140. Available from: https://doi.org/10.4067/S0717-95022019000100136

[5] Bogart BI, Ort V. Elsevier's Integrated Anatomy and Embryology E-Book. Saintt Louis: Mosby; 2007.

[6] Dore R. Pyramide de Lalouette [Lalouette's pyramid]. Union Med Can. 1951;80(6):733-734. Available from: https://pubmed.ncbi.nlm.nih.gov/14836035/

[7] Cicekcibasi AE, Salbacak A, Seker M, Ziylan T, Tuncer I, Buyukmumcu M. Developmental variations and clinical importance of the fetal thyroid gland: a morphometric study. Saudi Medical Journal. 2007:28(4):524-528.

[8] Al-Azzawi A, Takahashi T. Anatomical variations of the thyroid gland: an experimental cadaveric study. Annals of Medicine and Surgery. 2021;70:102823. Available from: https://doi.org/10.1016/j.amsu.2021.102823 
[9] Akbulut A, Aydinbelge FN, Koca G, Kalayci S, Korkmaz M. Double pyramidal lobe at one thyroid lobe: a rare scintigraphic appearance. Nuclear Medicine and Biomedical Imaging. 2018;3(1). Available from: https://doi.org/10.15761/NMBI.1000134

[10] Mortensen C, Lockyer H, Loveday E. The incidence and morphological features of pyramidal lobe on thyroid ultrasound. Ultrasound. 2014;22(4):192-198. Available from: https://doi.org/10.1177/1742271X14554677

[11] Sinos G, Sakorafas GH. Pyramidal lobe of the thyroid: anatomical considerations of importance in thyroid cancer surgery. Oncology Research and Treatment. 2015;38(6):309-310. Available from: https://doi.org/10.1159/000430894

[12] Kim DW, Ha TK, Park HK, Kang T. Sonographic detection of thyroid pyramidal lobes before thyroid surgery. Journal of Ultrasound in Medicine. 2014;33(2):239-244. Available from: https://doi.org/10.7863/ultra.33.2.239

[13] Gurleyik E, Gurleyik G, Dogan S, Cobek U, Cetin F, Onsal U. Pyramidal Lobe of the thyroid gland: surgical anatomy in patients undergoing total thyroidectomy. Anatomy Research International. 2015;2015:1-5. Available from: https://doi.org/10.1155/2015/384148

[14] Cengiz A, Şakı H, Yürekli Y. Scintigraphic evaluation of thyroid pyramidal lobe. Malecular Imaging and Radionuclide Therapy. 2013 Aug 5;22(2):32-35. Available from: https://doi.org/10.4274/Mirt.09719
[15] Ayandipo OO, Afuwape OO, Soneye OY. Incidence of pyramidal thyroid lobe in the university college hospital Ibadan. Nigerian Journal of Clinical Practice. 2018;21(11):1450-1453. Available from: https://pubmed.ncbi.nlm.nih.gov/30417843/

[16] Braun EM, Windisch G, Wolf G, Hausleitner L, Anderhuber F. The pyramidal lobe: clinical anatomy and its importance in thyroid surgery. Surgical and Radiologic Anatomy. 2006;29(1):21-27. Available from: https://doi.org/10.1007/s00276-006-0165-1

[17] Zivic R, Radovanovic D, Vekic B, Markovic I, Dzodic R, Zivaljevic V. Surgical anatomy of the pyramidal lobe and its significance in thyroid surgery. South African Journal of Surgery. 2011;49(3):110-116. Available from: https://www.ajol.info/index.php/sajs/article/view/70492

[18] Dessie MA. Anatomical variations and developmental anomalies of the thyroid gland in Ethiopian population: a cadaveric study. Anatomy \& Cell Biology. 2018;51(4):243-250. Available from: https://doi.org/10.5115/acb.2018.51.4.243

Received: 2021-11-06

Revision Requested: 2022-01-27

Revision Received: 2022-02-19

Accepted: 2022-02-21 